\title{
A formação musical na educação infantil: a questão docente e as possibilidades da musicalização
}

Valéria Regina Botaro Kastein Faculdade Campos Elíseos - FCE, Brasil

Marsiel Pacífico

Universidade Federal do Amazonas - UFAM, Brasil

\begin{abstract}
RESUMO
A musicalização é um componente fundamental para a Educação Infantil, estando contemplada no Referencial Curricular Nacional para a Educação Infantil, visto que propicia o desenvolvimento da criança em seus aspectos cognitivos, afetivos, estéticos e sensoriais. Neste artigo, por meio de uma revisão de literatura da área como Rosa (1990), Girard (2004) e Brito (2003), demonstramos o evidente distanciamento do ideal formativo caro à música e as práticas pedagógicas dos profissionais da Educação Infantil. Apesar dos avanços históricos em relação à Educação Infantil, ainda encontramos uma grande defasagem nas práticas de musicalização nas escolas, o que pode ser compreendido como resultante de um conjunto de fatores, no qual, sobretudo, destacamos a falta da formação adequada, seja na formação inicial ou na continuada dos professores da Educação Infantil. Por fim, apontaremos alguns princípios que podem fundamentar uma prática musical mais rica, potencializadora do desenvolvimento da criança.
\end{abstract}

PALAVRAS-CHAVE: Prática pedagógica. Educação musical. Educação Infantil.

\section{THE MUSICAL FORMATION IN EARLY CHILDHOOD EDUCATION: THE TEACHING QUESTION AND THE POSSIBILITIES OF MUSICALIZATION}

\begin{abstract}
Musicalization is a fundamental component for early childhood education, being contemplated in the National Curriculum Framework for Early Childhood Education, since it propitiates the development of the child in its cognitive, affective, aesthetic and sensorial aspects. In this article, through a literature review of the area such as Rosa (1990), Girard (2004) and Brito (2003), we demonstrate the evident distancing of the formative ideal expensive to the music and the pedagogical practices of the professionals of the infantile education. Despite the historical advances in relation to early childhood education, we still find a great gap in the practices of musicalization in schools, which can be understood as resulting from a set of factors, in which, above all, we emphasize the lack of adequate training, initial or continuing education of teachers of Early Childhood Education. Finally, we will point out some principles that may support a richer, more potent musical practice, which will enhance the child's development.
\end{abstract}

KEY WORDS: Pedagogical practice. Musical education. Childhood education. 


\section{LA FORMACIÓN MUSICAL EN LA EDUCACIÓN INFANTIL: LA CUESTIÓN DOCENTE Y LAS POSIBILIDADES DE LA MUSICALIZACIÓN}

\section{RESUMEN}

La música es un componente fundamental para la educación infantil, estando contemplada en el Referencial Curricular Nacional para la Educación Infantil, ya que propicia el desarrollo del niño en sus aspectos cognitivos, afectivos, estéticos y sensoriales. En este artículo, por medio de una revisión de literatura del área como Rosa (1990), Girard (2004) y Brito (2003), demostramos el evidente distanciamiento del ideal formativo costoso a la música y las prácticas pedagógicas de los profesionales de la educación infantil. A pesar de los avances históricos en relación a la educación infantil, todavía encontramos un gran desfase en las prácticas de musicalización en las escuelas, lo que puede ser comprendido como resultante de un conjunto de factores, en el que, sobre todo, destacamos la falta de la formación adecuada, sea en la formación de los profesores de Educación Infantil. Por último, apuntaremos algunos principios que pueden fundamentar una práctica musical más rica, potencializadora del desarrollo del niño.

PALABRAS CLAVE: Práctica pedagógica. Educación musical. Educación Infantil.

\section{INTRODUÇÃO}

A linguagem musical esteve sempre presente na vida dos seres humanos. A música é um rico instrumento que pode fazer a diferença nas instituições de ensino, pois ela desperta a criança para um mundo prazeroso e satisfatório, facilitando a socialização e também a aprendizagem. Se a linguagem musical é um componente que acompanha nossa cultura desde seus primórdios, na vida de cada criança não é diferente:

O envolvimento das crianças com o universo sonoro começa ainda antes de seu nascimento, pois na fase intrauterina, os bebês já convivem com um ambiente de sons provocados pelo corpo da mãe, como o sangue que flui nas veias, a respiração e a movimentação dos intestinos. A voz materna também constitui material sonoro especial e referência para eles (BRITO, 2003, p. 35).

Deste modo, a prática da musicalização na Educação Infantil não deve ser compreendida como a pretensão de formar músicos ou professores de música, mas sim, por meio da vivência, manejo e compreensão da linguagem musical, propiciar a abertura de canais sensoriais, facilitando a expressão de emoções, ampliando a cultura geral e contribuindo para a formação integral do ser. Portanto, faz-se necessário que todos os professores tenham o contato com a educação musical durante suas etapas de formação.

A experiência musical enriquece o aprendizado, ajuda no desenvolvimento da expressão, do equilíbrio, da autoestima e autoconhecimento, além de favorecer a integração social. Devemos considerar que o trabalho com música é um meio de expressão e forma de conhecimento acessível aos bebês e às crianças. As atividades do ensino musical precisam 
oferecer, para a criança, a vivência de fatos musicais, com o propósito de garantir que ela utilize a linguagem musical e que adquira novos conhecimentos. A partir do presente artigo, pode-se perceber o quanto a música é importante para as crianças e o quanto ela tem a contribuir para o desenvolvimento infantil, desde que utilizada adequadamente. Embora tal reconhecimento seja consensual, a intensidade e a qualidade da prática pedagógica da musicalização estão aquém do ideal formativo.

Desse modo, este artigo por meio de uma pesquisa bibliográfica com revisão de literatura da área, busca inicialmente destacar a importância da musicalização para o desenvolvimento da criança em múltiplos aspectos, até chegarmos aos desafios da prática docente, que será discutida a partir das restrições na formação inicial, na falta de políticas de formação continuada e, por fim, em princípios que possam subsidiar o desenvolvimento de uma prática pedagógica formativa de musicalização.

\section{POR QUE MUSICALIZAR? A IMPORTÂNCIA DA INTELIGÊNCIA MUSICAL PARA O DESENVOLVIMENTO INFANTIL}

Gardner (1995) desenvolveu estudos que revolucionaram conceitos de ensino e aprendizagem ao antecipar descobertas da neurociência sobre a música. Desde o início da década de 1980, ele apontou a existência de uma Inteligência Musical que faz parte da Teoria das Inteligências Múltiplas, a qual nos ajudou a compreender que a aprendizagem de competências como Língua Portuguesa ou Matemática, por exemplo, são distintas mas também relacionais; o que resulta que a aprendizagem de uma coisa influi sobre a aprendizagem de outras, mas também que um sujeito pode desenvolver uma expertise em uma área ao mesmo tempo em que apresenta severas dificuldades com outros saberes. A Teoria das Inteligências Múltiplas sugere que existe um conjunto de habilidades, conhecidas como inteligências, e que cada pessoa as possui em grau e em combinações distintas. São sete inteligências: Musical, Corporal-cinestésica, Lógico-matemática, Linguística, Espacial, Interpessoal e Intrapessoal. Esse trabalho visa destacar a Inteligência Musical.

Segundo Gardner (1995), a Inteligência Musical se manifesta a partir de uma habilidade para apreciar, compor ou reproduzir uma peça musical. Inclui discriminação de sons, habilidade para perceber temas musicais, sensibilidade para ritmos, texturas e timbre, e habilidade para produzir e/ou reproduzir música. A criança pequena com habilidade musical especial percebe desde cedo diferentes sons no seu ambiente e, frequentemente, canta para si mesma. 
Destacam-se os motivos pelos quais a Inteligência Musical deve ser valorizada na escola, de acordo com Campbell, Campbell e Dickinson (2000) - a música transmite nossa herança cultural; merece ser desenvolvida, pois é uma aptidão inerente a todas as pessoas; permite a expressão de nossos sentimentos mais nobres e pensamentos, na medida em que é criativa e autoexpressiva; ensina os alunos sobre seus relacionamentos com as outras pessoas; proporciona uma melhora na aprendizagem de todas as matérias; oferece aos alunos sucesso que eles podem não encontrar em outra parte do currículo escolar; contribui com os alunos para que eles aprendam que nem tudo na vida é quantificável e, por fim, desenvolve o espírito humano.

Gardner (1995) destaca que as Inteligências correspondem a uma parte da herança genética humana e que todas se manifestam em todas as crianças, em algum grau, independentemente da educação ou apoio cultural. Porém, mesmo que um indivíduo possua grande potencial biológico para determinada habilidade, ele precisa de oportunidades para explorá-la e desenvolvê-la. Partindo deste pensamento, a escola deve respeitar as habilidades de cada um, e também oferecer o contato com atividades que trabalhem outras inteligências, mesmo porque, todas as atividades que realizamos utilizam mais de uma inteligência.

A música adquire, desde muito cedo, grande importância na vida de uma criança. Além de proporcionar sensações, por meio da experiência musical, são desenvolvidas capacidades que serão importantes durante o crescimento infantil.

O potencial da inteligência humana é condicionado pelos genes de cada indivíduo, porém são necessários estímulos para colocar essa inteligência em prática, e é justamente aí que entra a música. $\mathrm{O}$ estímulo sonoro aumenta as conexões entre os neurônios e quanto maior a conexão entre os neurônios, maior o potencial de desenvolvimento cognitivo, além dos inerentes desenvolvimentos afetivo e estético propiciados pela música (ILARI, 2003).

Desde os primeiros meses de vida, a criança consegue perceber sons e obter experiências sensoriais, estéticas e de linguagem por meio deles. É importante começar a educação musical desde o berçário, pois ela desenvolve capacidades como sensibilidade, intuição, reflexão, criatividade, coordenação motora, dicção e ritmo.

O trabalho com música deve considerar, portanto, que ela é um meio de expressão e forma de conhecimento acessível aos bebês e crianças, inclusive aquelas que apresentem necessidades especiais. A linguagem musical é excelente meio para o desenvolvimento da expressão, do equilíbrio, da autoestima e autoconhecimento, além de poderoso meio de integração social (BRASIL, 1998, p. 49). 
Hoje, sabe-se que o ensino musical é fundamental para o bom desenvolvimento das crianças. Segundo Girard (2004), a música é uma das poucas atividades que mexem simultaneamente com os dois hemisférios do cérebro, o esquerdo mais ligado à criatividade, à língua e às artes e o direito ligado às ciências exatas. A música amplia as vias neurais ao proporcionar esse estímulo bilateral. Além disso, a música estimula áreas do cérebro que não são desenvolvidas por outras linguagens, como a oral e a escrita. Assim, incentivar as crianças a ouvir música é muito importante porque enriquece o aprendizado, ajuda no desenvolvimento emocional e proporciona uma formação com maiores estímulos para o desenvolvimento cognitivo da criança.

O som ainda tem um efeito calmante sobre as crianças. As músicas têm uma pulsação que as crianças ouvem desde quando ainda estão na barriga da mãe. Outra vantagem é que, ao treinar o ouvido, fica mais fácil discriminar os sons dos instrumentos musicais, os sons pessoais, da natureza, entre outros. As crianças aprendem a diferenciar sons, ritmos e volume e percebem que um som pode ser agudo ou grave, longo ou curto, suave ou forte.

A música é um rico instrumento que pode fazer a diferença nas instituições de ensino, não é somente uma associação de sons e palavras, pois a música acorda o indivíduo para um mundo prazeroso e satisfatório para a mente e para o corpo, facilitando a socialização e também a aprendizagem do mesmo.

Segundo Bernardes, Oliveira e Rodriguez (2007), as crianças pequenas, por volta de um ano e meio, ainda não falam, mas se expressam por meio de movimentos, sons e ritmos. Elas adoram escutar música e expressam satisfação quando ouvem o canto dos pássaros, dos grilos, das cigarras. Os sons da natureza dão muito prazer às crianças. Esse contato com diferentes ruídos e sons traz novas descobertas, conhecimentos e permite a exploração do diferente, tornando-se muito importante para as crianças.

Porém, os barulhos como, por exemplo, de um avião, de um carro ou de uma sirene chamam a atenção da criança de uma forma diferente; muitas vezes esses ruídos incomodam. Mas, essas diferentes formas de sons e de experiências aumentam o repertório de sentimentos e linguagens.

Bernardes, Oliveira e Rodriguez (2007) ainda destacam que é através do próprio corpo e do ambiente ao redor da criança que ocorre a primeira descoberta dos sons e do ritmo. A criança vai rompendo os esquemas repetidos de suas experiências anteriores e assim, vai explorando novos caminhos. Quando as crianças ouvem um som, primeiramente elas prestam muita atenção e logo após elas tentam imitar, ou seja, tentam reproduzir o que ouviram. Elas tentam acompanhar a música cantando e fazendo movimentos com o corpo e sem saberem, 
estão desenvolvendo o senso do ritmo. Se a criança aprende a ouvir, ela pode recriar uma música. Para que a criação seja significativa no contexto de desenvolvimento da criança, é importante que o educador valorize todo ato de criação.

Outro ponto importante a ser destacado é que, quando uma criança acompanha uma música junto com seus colegas, ela se sente pertencendo ao grupo. No trabalho desenvolvido em sala de aula, o professor precisa ficar atento à seleção do repertório, oferecendo um repertório variado. Temos uma grande variedade de ritmos e instrumentos que devem ser apresentados e trabalhados com os alunos desde a Educação Infantil. Se o educador age dessa forma, apresentando essa riqueza musical, ele estará despertando nas crianças a curiosidade pelo novo e o respeito pelos colegas de outras regiões.

O adulto é um o maior modelo de imitação da criança, por isso é importante que ele seja criativo e crítico na escolha do que oferecer a ela. Dessa forma, ele estará garantindo que as atividades sejam interessantes para todos. A valorização da iniciação musical na Educação Infantil oferece às crianças novas ferramentas para lidar com o mundo. Quando estão cantando, as crianças trabalham muitas coisas importantes como sua concentração, memorização, consciência corporal e coordenação motora, principalmente porque, junto com o ato de cantar, ocorre geralmente o desejo de mexer o corpo, acompanhando o ritmo e criando novas formas de dança e expressão corporal.

O importante, ao cantar músicas com as crianças, é respeitar interesses individuais e também específicos de cada fase do desenvolvimento; assim, elas podem mostrar maior interesse por temas relacionados a super-heróis, seres mágicos, animais ou assuntos como amizade.

Para uma visão cognitivista, o conhecimento musical se inicia por meio da interação com o ambiente, através de experiências concretas, que aos poucos levam à abstração. A criança se envolve integralmente com a música e a modifica constantemente, transformando-a, pouco a pouco, numa resposta estruturada (ROSA, 1990, p. 15).

Vale lembrar que ouvir música não deve ser uma atividade imposta e sim realizada com prazer, pois somente assim os benefícios serão obtidos de forma natural.

De acordo com Costa e Valle (1971), a música em sala de aula pode ajudar a criar um ambiente emocional positivo que favoreça a aprendizagem, pois existe uma forte conexão entre a música e as emoções. A música também pode ser utilizada para aumentar o suspense, a tristeza, a tragédia ou a alegria das histórias. Ela pode ainda ser utilizada ou criada para expressar o humor. As músicas humorísticas podem criar um ambiente caloroso e receptivo na sala de aula. As brincadeiras musicais aprimoram as habilidades de audição e concentração. 
Quando a criança canta ou toca em conjunto, sente que faz parte de um todo onde todos os elementos são igualmente importantes. Compreende, portanto, que cada pessoa precisa colaborar individualmente, mas que todos precisam trabalhar em harmonia, com um objetivo comum. A criança adquire essa compreensão ao constatar que o sucesso da execução de um número de coro, se encontra na dependência direta da harmonia de seus executantes (COSTA; VALLE, 1971, p. 11).

A música pode ser utilizada para propósitos específicos, como por exemplo: para relaxar, revigorar, concentrar a atenção do aluno ou até mesmo para facilitar as transições.

\section{DIFICULDADES DA PRÁTICA PEDAgógICA: A QUESTÃo DA FORMAÇÃo DOCENTE}

Registros históricos evidenciam que a música é conhecida e praticada desde a préhistória. Provavelmente a observação dos sons da natureza tenha despertado no homem a vontade ou necessidade de uma atividade que se baseasse na organização de sons. A música sempre esteve associada às culturas e tradições de cada época. É incontestável que a música faz parte de nossa vida. Ela está presente em muitos momentos e há muito tempo está sendo estudada como uma importante aliada do desenvolvimento das pessoas. Uma educação musical adequada e bem trabalhada pode auxiliar na compreensão de aspectos de nossa língua, de nossos costumes, de nossa história e de nossa realidade nacional.

O professor tem o importante papel de fazer com que a criança descubra, analise e compreenda os ritmos do mundo, por meio da observação e do contato com instrumentos musicais, com o teatro, a dança, o folclore, etc.

As atividades musicais contribuem para que o indivíduo aprenda a viver na sociedade, abrangendo aspectos comportamentais como disciplina, respeito, gentileza e polidez e aspectos didáticos, com a formação de hábitos específicos, tais como os relativos a datas comemorativas, a noções de higiene, a manifestações folclóricas e outros (ROSA, 1990, p. 22).

A educação musical precisa se tornar um componente comum da prática pedagógica (VEIGA, 1992) da Educação Infantil, seja nas atividades de educação musical ou integradas aos outros saberes da Educação Infantil, e isso somente ocorrerá se houver uma conscientização cada vez maior da importância do desenvolvimento da expressividade da criança e da criação de oportunidades para que a criatividade esteja presente no trabalho em sala de aula. 
O trabalho com a linguagem musical pode e deve ser muito rico e diversificado. Os bons resultados no ensino da música serão alcançados pela adequação das atividades, pela postura reflexiva e crítica do professor, facilitando a aprendizagem, proporcionando situações enriquecedoras, organizando experiências que garantam a expressividade das crianças.

De acordo com o RCNEI, a prática pedagógica da musicalização na Educação Infantil é componente fundamental e específico, devendo ser trabalhado pelo(a) professor(a) pedagogo(a) responsável. Na área da Educação Infantil, o debate sobre a formação de professores sempre partiu da ênfase do desenvolvimento infantil nos anos iniciais. O conhecimento que existe sobre essa etapa do desenvolvimento humano e sobre como as crianças pequenas se desenvolvem no ambiente escolar tem sido um dos pressupostos básicos para o delineamento da formação prévia e em serviço dos profissionais que trabalham nas creches e nas pré-escolas.

A discussão sobre a formação do professor de Educação Infantil aumentou com a publicação da Lei no $.9394 / 96$ que, em seu artigo 87, § 4º determina: “Até o fim da Década da Educação, somente serão admitidos professores habilitados em nível superior ou formados por treinamento em serviço" (BRASIL, 1996).

Uma das maiores dificuldades do ensino de música na Educação Infantil são as restrições na formação dos docentes que atuam neste nível de ensino. Demanda-se deste profissional competência técnica e sensibilidade estética para desenvolver o trabalho de sensibilização junto às crianças. Mas quando observamos os dados sobre a qualificação dos profissionais que atuam na Educação (GATTI, 2010), e em específico na Educação Infantil (GARANHANI, 2010), com certeza, percebemos que essa é uma questão muito complexa. Sabemos que o profissional da Educação Infantil não deve apenas cuidar da criança; hoje se busca a união entre o cuidar e o educar. Em um contexto de um país tão amplo e diverso em suas características sociais, culturais e históricas, devemos lembrar que, em muitos municípios do território nacional, apesar dos inegáveis avanços recentes, a Educação Infantil é delegada a profissionais sem formação superior (TENENTE, 2017). Isso ocasiona a inserção de profissionais sem qualificação para as funções que exercerão, o que faz com que o trabalho na Educação Infantil seja realizado por professores leigos.

Felizmente não podemos generalizar, pois existem profissionais altamente qualificados para exercerem sua função. Todas as crianças têm direito a uma educação de qualidade. Falar sobre isto nos remete a uma reflexão sobre a relação criança/adulto, à qualidade das intervenções desse adulto no cotidiano das crianças, ou seja, à própria formação do profissional. Por outro lado, ainda quando falamos de professores com a devida instrução obtida em nível 
superior, os cursos de Pedagogia comumente não oferecem atenção suficiente para a questão da musicalização em sua matriz curricular, o que propicia a formação de docentes que não estarão capacitados minimamente para o desenvolvimento da educação musical em suas práticas pedagógicas.

De acordo com Knoener (2006), o profissional de Educação Infantil atua como mediador no processo de desenvolvimento e aprendizagem, por isso sua formação merece atenção especial. Para atuar na Educação Infantil, é necessária uma qualificação específica, incluindo o conhecimento das bases científicas do desenvolvimento da criança, da produção de aprendizagens e da habilidade de reflexão sobre a prática. Além da formação acadêmica prévia, é importante a formação permanente, inserida no trabalho pedagógico, nutrindo-se dele e renovando-o constantemente.

O professor deve, a partir da Educação Infantil, trabalhar as habilidades básicas, incluindo a linguagem artística em todas as suas formas, por meio da música, do desenho, da pintura, da dança e da representação. Por isso é importante que a formação do professor ofereça preparo adequado para a educação musical, pois esta pode contribuir muito com o desenvolvimento e a aprendizagem dos alunos. Somente com as competências necessárias para a educação musical contempladas em sua formação, o professor poderá construir relações interdisciplinares entre a música e os diversos temas e conteúdos da Educação Infantil, favorecendo não só o desenvolvimento das crianças com os ganhos inerentes à musicalização, mas também propiciando aulas mais atrativas e significativas, à medida que estas se tornam municiadas pela ludicidade.

Nesse sentido, notamos que a falta da capacitação na área ou a escassez de profissionais específicos, como os licenciados em música, produzem um processo educacional de musicalização permeado por vícios e pela falta de uma intencionalidade pedagógica rica, que deveria ser municiada pelos fundamentos do ensino de música, dentro de seu complexo arcabouço didático.

Ocorre que, muitas vezes, o trabalho do professor em relação à música é prejudicado pela falta de uma formação musical adequada e um receio em relação a expressar-se musicalmente. Em muitos cursos de graduação, essa formação nem é contemplada por uma disciplina específica ou pela ementa de outros campos do saber. O docente não tem nenhum contato com música durante todos os anos de sua formação. Em nosso País, o espaço destinado à música, em grande parte dos currículos de formação de professores, é ainda incipiente, quando existe. É preciso investir significativamente na formação musical de nossos professores, se realmente queremos obter melhores resultados na educação. Por meio da música, o professor 
pode explorar a criatividade dos alunos e uma vez desenvolvido, o pensamento criativo influencia nas diversas áreas da vida pessoal, enriquecendo o aluno e as demais pessoas ao seu redor.

\section{EDUCAÇÃO MUSICAL: PRINCÍPIOS PARA UMA PRÁTICA PEDAGÓGICA}

Apesar da escassez da formação em educação musical, há profissionais da Educação que compreendem a linguagem musical como importante para os alunos, mas, ao mesmo tempo, têm receios porque se acham desafinados, ou não tocam um instrumento ou não sabem por onde começar. O que ajuda muito é um planejamento das aulas que inclua a preocupação constante com a linguagem musical, pois a música não pode ficar restrita a eventos como festas e datas marcantes, mas deve ser uma prática diária.

De acordo com Girard (2004), o professor precisa planejar o momento em que irá trabalhar com a música. Trabalhar somente a letra da música não é fazer educação musical, nesse caso, o professor está trabalhando apenas poesia. Também é um equívoco trabalhar a música apenas em ocasiões especiais. É importante que se faça um planejamento a longo prazo. O professor também deve evitar o uso da música somente para formar hábitos e atitudes, como escovar os dentes, lavar as mãos, ou para ajudar na memorização de letras do alfabeto e números. Músicas como estas costumam ser acompanhadas por gestos corporais que são imitados de forma mecânica e sem criatividade pelas crianças.

[...] muitas instituições encontram dificuldades para integrar a linguagem musical ao contexto educacional. Constata-se uma defasagem entre o trabalho realizado na área de Música e nas demais áreas do conhecimento, evidenciada pela realização de atividades de reprodução e imitação em detrimento de atividades voltadas à criação e à elaboração musical. Nesses contextos, a música é tratada como se fosse um produto pronto, que se aprende a reproduzir, e não uma linguagem cujo conhecimento se constrói (BRASIL, 1998, p. 47).

Sabemos que atualmente existe uma grande diversidade de músicas. Uma proposta de ensino que leve em consideração essa diversidade necessita abrir espaço para que o aluno traga música para a sala de aula. Cabe ao docente acolher, contextualizar e oferecer acesso a obras que sejam significativas para o desenvolvimento pessoal dos discentes em atividades de produção e apreciação.

Para Girard (2004), é preciso começar pela ampliação do repertório. A criança pode ouvir de tudo, não só músicas infantis, mas os mais variados estilos, do folclore à MPB, do erudito ao jazz. As atividades se complementam em um conteúdo integral, cujo objetivo é 
ensinar uma linguagem que a criança poderá compreender e com a qual poderá se expressar: a da música.

Ainda segundo Girard (2004), a música clássica é a melhor indicação para ser oferecida aos bebês, porque esse tipo de som tem batida semelhante ao ritmo cardíaco em repouso, despertando na criança a sensação semelhante à que ela tem quando colocada próxima ao coração da mãe. Também é verdade o contrário. Por exemplo, o som de um rock, em geral, tende a deixar a criança mais agitada. Porém a influência da música vai muito além de acalmar ou agitar bebês e crianças.

Com crianças de até três anos, o professor pode iniciar o trabalho com música levando instrumentos musicais (sejam eles ofertados pela escola ou construídos junto aos alunos) para a sala de aula e deixando-os à disposição de todos. Pode-se ainda introduzir experiências musicais que favoreçam o desenvolvimento de habilidades perceptivas e sonoras, como por exemplo, imitar vozes de outras pessoas ou sons de animais.

O papel do professor é estimular o gosto pela música e aumentar a familiaridade com essa linguagem. Sendo assim, o professor pode incentivar as crianças a cantar, além de educálas musicalmente ao brincar com a voz, explorando possibilidades diversas como imitar ruídos e sons de trovão, animais, etc. O professor também deve incentivar bons hábitos, como por exemplo, manter-se relaxado e com boa postura, respirar tranquilamente e não gritar ou forçar a voz.

Os docentes também devem criar situações de aprendizagem nas quais as crianças possam estar em relação com diferentes tipos de produções musicais. As atividades de música nas escolas devem partir dos conhecimentos que as crianças já possuem. Todavia, nas formações dos licenciados em Música, geralmente ocorre um processo de enfoque na música que restringe o aspecto didático e a abertura para receber o conhecimento prévio dos alunos:

No entanto, é preciso considerar que as escolas especializadas, de qualquer tipo, configuram um espaço de atuação que mantém o valor da prática musical em si, tendo correntemente como referência a música erudita e práticas pedagógicas de caráter técnico-profissionalizante. Assim, as escolas especializadas "confirmam" uma concepção de música e de prática pedagógica que não é compatível com as exigências desafiadoras das escolas públicas de ensino fundamental e médio, sendo certamente mais "atraentes e protetoras" do que o espaço de trabalho da escola regular, com seus inúmeros desafios (PENNA, 2002, p. 17).

É importante destacar que trabalhar com música não é simplesmente cantar; o ato de produzir diferentes sons, em diferentes ritmos também é uma atividade musical. A fabricação de instrumentos em sala de aula é uma atividade muito interessante que desperta o interesse dos 
alunos, pois quando eles têm a oportunidade de fabricar seus próprios instrumentos, eles demonstram maior compreensão da música, além de gostarem da atividade manual. São diversos os materiais que possuem potencial musical como: latas, garrafas, papelão ondulado, pedaços de madeira, galhos secos, bambu, lixas, linhas de pescar, tampas de panelas, e outros materiais diversificados que depois de fabricados poderão ser decorados. A partir desses instrumentos, o professor pode desenvolver diversas atividades, individualmente, em grupos ou até mesmo com toda a sala, surgindo uma orquestra.

O Referencial Curricular Nacional para a Educação Infantil aborda que os conteúdos a serem trabalhados estão organizados em dois blocos: o fazer musical e a apreciação musical.

O fazer musical é uma forma de comunicação e expressão que acontece por meio da improvisação, da composição e da interpretação. Improvisar é criar instantaneamente, orientando-se por alguns critérios pré-definidos, mas com grande margem a realizações aleatórias, não-determinadas. Compor é criar a partir de estruturas fixas e determinadas e interpretar é executar uma composição contando com a participação expressiva do intérprete (BRASIL, 1998, p. 57).

O uso da música na educação da criança também deve ser mediado pelas dimensões históricas, sociais e culturais, envolvendo componentes fundamentais para a aprendizagem infantil, como a ludicidade e o prazer:

Ensinar arte em consonância com os modos de aprendizagem do aluno, significa, então, não isolar a escola da informação sobre a produção histórica e social da arte e, ao mesmo tempo, garantir ao aluno a liberdade de imaginar e edificar propostas artísticas pessoais ou grupais com base em intenções próprias. E tudo isso integrado aos aspectos lúdicos e prazerosos que se apresentam durante a atividade artística (BRASIL, 1997, p. 47).

Assim, destacamos a diversidade de iniciativas e práticas que o docente poderá conduzir junto aos alunos da Educação Infantil, como componentes fundamentais a serem incorporados nas práticas pedagógicas. Dado à diversidade de estímulos possíveis, os variados ganhos de desenvolvimento dos alunos e o amplo repertório que a música oferece em si e na conjugação didática com outros componentes curriculares, faz-se necessário que a musicalização ganhe espaço e vez na Educação Infantil.

\section{CONSIDERAÇÕES FINAIS}

A partir das discussões iniciais propostas neste artigo, pudemos concluir que a música deve fazer parte da vida escolar das crianças, pois elas demonstram grande interesse e entusiasmo pela mesma, além do processo de musicalização garantir, em suas especificidades, 
aspectos singulares para o desenvolvimento cognitivo e motor da criança. Por isso é relevante que o professor realize trabalhos musicais, ainda que não tenha o propósito de formar músicos, mas sim com a intenção de contribuir para o desenvolvimento e a aprendizagem das crianças.

Ademais a necessidade formativa da criança, na Educação Infantil, vem ao encontro das possibilidades da música, à medida que suas constituições simbólicas, motoras e cognitivas demonstram clara afinidade com a ludicidade e o ritmo que a musicalização proporciona.

Todavia é necessário que os educadores saibam como trabalhar com música na escola e que tenham consciência de sua importância, pois algumas leis e documentos abordam a música como conteúdo obrigatório do componente curricular. Mas será que os cursos estão realmente preparando os professores para esta tarefa?

Assim sendo, o ensino da música deve ser visto como algo que só tem a contribuir com o desenvolvimento e a aprendizagem das crianças e também com o trabalho do professor, devendo-se buscar o conhecimento musical para que se conquiste uma educação cada vez melhor. Se, por um lado, cabe a cada educador e profissional envolvido com a educação fazer a sua parte para, juntos, obterem sucesso, por outro aspecto, fica evidenciado que as intenções anunciadas nos Parâmetros Curriculares e nos documentos legais acerca da importância da música no processo formativo da infância, acabam por não se efetivar na prática devido à falta de recursos objetivos (como materiais didáticos e instrumentos musicais), capacitação técnica dos docentes em nível de formação inicial e continuada, e pela falta de uma política de implementação das práticas pedagógicas concernentes à musicalização.

\section{REFERÊNCIAS}

BERNARDES, Maria José; OLIVEIRA, Miriam S. L.; RODRIGUEZ, Marta A. A música na creche. In: ROSSETTI-FERREIRA, Maria Clotilde et al. (Orgs.). Os fazeres na educação infantil. 9a ed., São Paulo: Cortez, 2007.

BRASIL. Ministério da Educação e do Desporto. Secretaria de Educação Fundamental. Referencial Curricular Nacional para a Educação Infantil. Brasília: MEC/SEF, 1998. v. 3. Disponível em: 〈http://portal.mec.gov.br/seb/arquivos/pdf/volume3.pdf>. Acesso em: 10 nov. 2016.

Lei n. 9394. Lei de Diretrizes e Bases da Educação Nacional, de 20 de dezembro de 1996. Estabelece as diretrizes e bases da educação nacional. Disponível em: <http://www.planalto.gov.br/ccivil_03/Leis/L9394.htm>. Acesso em: 10 nov. 2016.

. Brasil. Secretaria de Educação Fundamental. Parâmetros curriculares nacionais: arte. Secretaria de Educação Fundamental. Brasília: MEC/SEF, 1997. 130p. 
KASTEIN, V.R.; PACİFICO, M.

BRITO, Teca Alencar de. Música na educação infantil: propostas para a formação integral da criança. 2. ed. São Paulo: Petrópolis, 2003.

CAMPBELL, Linda; CAMPBELL, Bruce; DICKINSON, Dee. Ensino e aprendizagem por meio das inteligências múltiplas. 2.ed., Porto Alegre: Artes Médicas, 2000.

COSTA, Niobe Marques da; VALLE, E. A. del. Música na escola primária. 4. ed., Rio de Janeiro: Livraria José Olympio Editora, 1971.

GARANHANI, Marynelma C. A docência da educação infantil. In: SOUZA, Gizeli. (Org.). Educar na infância: perspectivas histórico-sociais. São Paulo: Contexto, 2010. p. 187-200.

GARDNER, Howard. Inteligências múltiplas: a teoria na prática. Porto Alegre: Artes Médicas, 1995. 257 p.

GATTI, Bernardete A. Formação de professores no Brasil: características e problemas. Educ. Soc., Campinas, v. 31, n. 113, p. 1355-1379, out./dez. 2010. Disponível em: <http://www.scielo.br/pdf/es/v31n113/16.pdf>. Acesso em 10 de fev. 2017.

GIRARD, Giovana. Música para aprender e se divertir. Nova Escola, ano XIX, n. 173, São Paulo, p. 55-57, 2004.

ILARI, Beatriz. A música e o cérebro: algumas implicações do neurodesenvolvimento para a educação musical. Revista da ABEM, Porto Alegre, v. 9, p. 7-16, set. 2003.

KNOENER, Sandra Heinz. O ensino das artes na escola: a ótica dos professores de educação infantil. 2006. Dissertação (Mestrado em Educação) - Universidade do Oeste de Santa Catarina - UNOESC, Joaçaba, SC, 2006.

PENNA, Maura. Professores de música nas escolas de ensino fundamental e médio: uma ausência significativa. Revista da ABEM, p. 7-19, set. 2002.

SANTA ROSA, Nereide S. Educação musical para a pré-escola. São Paulo: Ática, 1990.

TENENTE, Luiza. 35\% dos professores de educação infantil não têm diploma: entenda a importância da formação em pedagogia. G1-Globo.com, 22 jun. 2017. Disponível em: $<$ https://g1.globo.com/educacao/guia-de-carreiras/noticia/ 35-dos-professores-de-educacaoinfantil-nao-tem-diploma-entenda-a-importancia-da-formacao-em-pedagogia.ghtml>. Acesso em: 5 jul. 2018.

VEIGA, Ilma Passos Alencastro. A prática pedagógica do professor de didática. 2. ed. Campinas, Papirus, 1992.

\section{SOBRE OS AUTORES}

Valéria Regina Botaro Kastein é professora na educação infantil em Descalvado, SP, pedagoga, especialista em Psicomotricidade, Educação Ambiental, Ludopedagogia, Ensino de Artes e Educação Especial e Inclusiva.

E-mail: safce.artigo@gmail.com 
Marsiel Pacífico é Doutor em Educação pela Universidade Federal de São Carlos (UFSCar) e Professor Adjunto no Departamento de Métodos e Técnicas da Universidade Federal do Amazonas (UFAM). E-mail: marsiellp@gmail.com

Recebido em março de 2018 Aprovado em setembro de 2018 